\title{
Maximizing the Common Good of Audience Under Impartiality by Framing in the Processing of Interpreting*
}

\author{
REN Rui, DING Hui, LI Yang \\ Northeastern University, Shenyang, China

\begin{abstract}
Interpreting is cross-cultural communication, in which audience is at the end. When the success of communication or interpreting is concerned, indubitably, the good of audience in interpreting should be the ultimate goal of one interpreting task. Framing can change things a lot even the same message being conveyed. Framing in interpreting has not been stressed in the output of interpreting. Different types of interpreting and different types of audience should be dealt with different framing devices in order to maximize the common good
\end{abstract} \\ of the audience.
}

Keywords: the common good, audience, framing, interpreting, processing

\section{Introduction}

According to AUSIT Code of Ethics and Code of Conduct for Interpreters and Translators (2012 version), in code of ethics, general principles "professional conduct" and "impartiality" involve impartiality that interpreters need to follow.

\section{Professional Conduct}

Interpreters and translators act at all times in accordance with the standards of conduct and decorum appropriate to the aims of AUSIT (Australian Institute of Interpreters and Translators), the national professional association of interpreting and translation practitioners.

Explanation: Interpreters and translators take responsibility for their work and conduct; they are committed to providing quality service in a respectful and culturally sensitive manner, dealing honestly and fairly with other parties and colleagues, and dealing honestly in all business practices. They disclose any conflict of interest or any matter that may compromise their impartiality. They observe common professional ethics of diligence and responsiveness to the needs of other participants in their work. ${ }^{1}$

\section{Impartiality}

Interpreters and translators observe impartiality in all professional contacts. Interpreters remain unbiased throughout

\footnotetext{
* Acknowledgements: This research is funded by Education Department, Liaoning Province, China. The Project of Humanities and Social Sciences (No. W2012038) is headed by REN Rui.

REN Rui, associate professor, master, English Department, Northeastern University. Doctor candidate of Foreign Philosophy at School of Philosophy and Society, Jilin University.

DING Hui, postgraduate, English Department, Northeastern University.

LI Yang, undergraduate, English Department, Northeastern University.

${ }^{1}$ See http://ausit.org/AUSIT/Documents/Code_Of_Ethics_Full.pdf.
} 
the communication exchanged between the participants in any interpreted encounter. Translators do not show bias towards either the author of the source text or the intended readers of their translation. ${ }^{2}$

Explanation: Interpreters and translators play an important role in facilitating parties who do not share a common language to communicate effectively with each other. They aim to ensure that the full intent of the communication is conveyed. Interpreters and translators are not responsible for what the parties communicate, only for complete and accurate transfer of the message. They do not allow bias to influence their performance; likewise they do not soften, strengthen or alter the message being conveyed. ${ }^{3}$

The principle of impartiality is clearly clarified as above and it is one of the basics that professional interpreters must follow. And there was nothing to doubt that traditionally interpreters were asked to be "invisible", "impartial", and "neutral" in interpreting. However, the reality is that it is also common sense today that interpreters are not "invisible", "neutral", and "conduit", but "visible", "active controller of language", or "mediator" (Gile, 1995; Angelelli, 2004a, 2004b; REN, 2014, 2010; SU, 2010). According to the survey done by Angelelli (2004a, 2004b), visibility of interpreters was the fact found. And in translation, there has long been reader-centered translation (Holub, 1992). Similar question could be researched in interpreting, since visibility of interpreters is just a fact evident in interpreting such as medical interpreting. A reasonable inference could be in community interpreting or court interpreting, in which without doubt audience should be focused on and tilted toward. "The common good" and "framing" are two terms borrowed from social sciences to be utilized in discussing how to deal with audience in interpreting.

\section{The Common Good of Audience in Interpreting}

The term of "the common good" is so popular in the world in part owing to books by John Rawls, $A$ Theory of Justice (1971) and Justice as Fairness (2001), in which the distinction was made "between the Good, that is actively creating a better world however that may be defined, and the Just, which creates a fair, liberal social infrastructure that allows the pursuit of virtue...". 4

As to common good, there are three explanations given by Wikipedia as follows:

Explanation one: In philosophy, ethics, and political science the common good (also common wealth or common weal) is a specific "good" that is shared and beneficial for all or most members of a given community. The good that is common between person A and person B may not be the same as between person A and person C. Thus the common good can often change, although there are some things— such as the basic requirements for staying alive: food, water, and shelter- that are always good for all people.

Explanation two: Starting from "utilitarianism", the common good has sometimes been seen as a utilitarian ideal, thus representing "the greatest possible good for the greatest possible number of individuals". The "greatest possible number of individuals" would mean all human beings.

Explanation three: It originates from "the quintessential goal of the state, requires an admission of the individual's basic right in society, which is, namely, the right of everyone to the opportunity to freely shape his life by responsible action, in pursuit of virtue and in accordance with the moral law. The common good, then, is the sum total of the conditions of social life which enable people the more easily and straightforwardly to do so. The object of State sovereignty is the free choice of means for creating these conditions". 5

\footnotetext{
${ }^{2}$ See http://ausit.org/AUSIT/Documents/Code_Of_Ethics_Full.pdf.

3 See http://ausit.org/AUSIT/Documents/Code_Of_Ethics_Full.pdf.

${ }_{5}^{4}$ See https://en.wikipedia.org/wiki/Common_good.

${ }^{5}$ See https://en.wikipedia.org/wiki/Common_good.
} 
The common good of audience in interpreting refers to the great possible good for the great possible number of individuals of audience in interpreting when understanding of the information conveyed by the speaker and good communication between the speaker and audience is of great significance, and to "ensure that the full intent of the communication is conveyed" (AUSIT, 2012). If we take the communication in interpreting as the ring of the speaker-interpreter-audience, of which the audience is the end. In detail, the common good of the community could be depicted as the "complete and accurate transfer of the message" to the audience (AUSIT, 2012). Audience could be seen as a community. The common good of such a community should be emphasized. As long as impartiality is followed generally, the common good of the audience should be taken as the most important goal for a successful interpreting of the interpreter. Referring to explanation one by Wikipedia, correspondingly, in interpreting, the good should be shared and beneficial for all or most members of the community of audience. In pursuit of the good, the right of every audience is taken into consideration, though certainly the good of the majority is undoubtedly over that of the individual and the good of the individual is sure to be sacrificed for the sake of the majority. So only the majority of the community is discussed and taken as the common good of the audience. Framing is one way to maximize the common good of the audience.

\section{Frames and Framing}

Consciously or not, people live with frames, which are both part of human communication and human social life. Frames are well-recognized or accepted by groups or societies. "The concept frame is useful for the description of the way our knowledge is organised and how we use our knowledge in understanding" (Ensink \& Sauer, 2003, p. 4). One often cited example in formulating the concept of frame was given by Marvin Minsky:

What happens when a child reads a story that begins like this?

Mary was invited to Jack's party.

She wondered if he would like a kite.

If you asked what that kite was for, most people would answer that it mustbe a birthday present for Jack. How amazing it is that every normal personcan make such complicated inferences so rapidly—considering that the idea a gift was never mentioned at all! Could any machine do such remark-ble things? Consider all the other assumptions and conclusions that almost everyone will make: The party is a birthdayparty. Jack and Mary are children. "She" is Mary. "He" is Jack. She is considering giving Jack a kite.She wonders if he would like the kite.

We call these understandings "common sense". (Minsky, 1986, p. 261)

People live in the world as social beings when act as individuals in groups or societies have frames to help them understanding each other in terms of social life. Ensink and Sauer categorize two kinds of frames, namely, knowledge frames and interactive frames (Ensink \& Sauer, 2003, pp. 4-6). A knowledge frame is "a cognitively available pattern used in perception in order to make sense of the perceived material by 'imposing' that pattern and its known features on that material" (Ensink \& Sauer, 2003, p. 5). According to Ensink and Sauer, though no definition could be given to an interactive frame, different scholars have described similar interactions in human life (Ensink \& Sauer, 2003, p. 6). For instance, John Gumperz (1982).

The identification of specific conversational exchanges as representative of socio-culturally familiar activities is the process I have called "contextualization"... It is the process by which we evaluated message meaning and sequencing 
patterns in relation to aspects of the surface structure of the message, called "contextualization cues". The linguistic basis for this matching procedure resides in "co-occurrence expectations", which are learned in the course of previous interactive experience and form part of our habitual and instinctive linguistic knowledge. Co-occurrence expectations enable us to associate styles of speaking with contextual presuppositions. We regularly rely upon these matching procedures in everday conversation. (Gumperz, 1982, p. 162)

Fauconnier and Sweetser also give explanation to frames as follows:

These frames allow us to make maximal use of the data we are given in crucial respects; for example, if someone talking about a house mentions the front door, the bathroom door, or the driveway, we don't ask what front door? We that there is a probably a front door, simply from a complex understanding of the kind of object in question. (Fauconnier \& Sweetser, 1996, p. 5)

Evidently, frames are relative information of objects or matters in daily life that we are familiar with. When certain objects or matters are mentioned, people can get readily put in corresponding places in their human understanding systems. Such kind of activity in mind could be described as framing. Undoubtedly, framing is far from an action by only one individual. Instead, it is a social activity concerning a group of people or a community that has the schemata of interpretation together, by which people of the same community could locate, perceive, identify, and label things in same ways.

\section{Maximizing the Common Good by Means of Preferrable Framing to the Audience}

Impartiality is the first principle should be observed in interpreting, under which the common good of audience could be maximized by framing. In interpreting, understanding of what the speaker says is the good for the audience. Framing is one crucial element of understanding. Maximizing the common good of audience means framing should be chosen to help audience understand the message conveyed by the speaker.

In social theory, framing is a schema of interpretation, a collection of anecdotes and stereotypes, which individuals rely on to understand and respond to events (Goffman, 1974, p. 21). In other words, people build a series of mental "filters" through biological and cultural influences. They then use these filters to make sense of the world. The choices they then make are influenced by their creation of a frame.

In interpreting, interpreter is the framer of the information conveyed by the speaker. The choice of framing by the interpreter could surely influence how audience will interpret the message conveyed by the speaker. Interperters could help audience choose framing and build the mental shortcut and filters.

To be specific, in terms of interpreting, in order to maximize the common good of audience, three devices should be utilized. First, person utilized in the interpreted message should be preferrable to the audience. As to person, audience should be addressed in a polite manner in which the choice of person could make audience feel comfortable as part of the communication when dealing with sentences even without person in English. The good of the speaker should be secondary to that of audience. Taking the example of interperting from English into Chinese, interpreters should use “您” (níng) if necessary although “you” in English could be interpreted into both “你” (nĩ) and “您” (níng) in the target language of Chinese and there is no 您 (níng) at all in the source language of English. Second, interpreter should choose the most preferrable language to the audience so as to achieve the best result of conveying the message by the speaker. The style of the source language should be changed into the preferrable style to the audience. Third, The maximal appreciation and reception of interpreting by audience should be the goal for interpreter's work. For example, "He was beaten 
down by others" (LIU, 2010, p. 41). Different versions could be given to interpret it into Chinese. A mimic sentence could be "He was beaten by others". For such an English sentence, it could be interpreted into Chinese as “别人打了他”, “他被人打啦”, “他被人揍啦”, and “他挨揍啦”. The last version is the most amusable. If such an interpretation were chosen by the interpreter, audience could be entertained to the maximum degree. As far as the community of audience is concerned, the common good of the majority should be the most preferential. In this respect, the types of audience of one interpreting task should be taken into consideration. Person and style of language in interpreting should be the most preferrable to the majority of the audience.

\section{Conclusion}

The position of audience in interpreting has seldom been discussed in a preferrable way. In translation, audience and reception has long been emphasized since the reception aesthetics theory proposed by Hohendahl (1977), audience response, "author-centered paradigm", "text-centered paradigm", and "reader-centered paradigm" have long been of heated discussion (Holub, 1992). However, audience-centered interperting is new. Yet any successful interpreting needs to attach importance to response by audience. Impartiality should be observed first. Then, the common good of audience should be maximized. Framing could change a lot in terms of audience response. Framing is one respect that interpreters should take into account so as to maximize the common good of audience, which could involve dealing person, style of language, voice projection, and so on. Audience responses should be guide in interpreter's deciding interpreting principles. To sum up, there are different devices to maximize the common good of audience in interpreteing linguistically and culturally. As long as such a topic is considered by interpreters, much could be researched and done in interpreting. Framing could help audience maximize their common good and to appreciate interpreting in bettering audience mental shortcut and filters.

\section{References}

Angelelli, C. V. (2004a). Medical interpreting and cross-cultural communication (p. 75). Cambridge: Cambridge University Press.

Angelelli, C. V. (2004b). Revisiting interpreter's role. Amsterdam: John Benjamins Publishing Company.

AUSIT. (n.d.). In Ausit. Retrieved from http://ausit.org/ AUSIT

Code of ethics. (2012). In Ausit. Retrieved from http://ausit.org/AUSIT/Documents/Code_Of_Ethics_Full.pdf

Common good. (n.d.). In Wikipedia. Retrieved from https://en.wikipedia.org/wiki/Common_good

Ensink, T., \& Sauer, C. (2003). Social-functional and cognitive approaches to discourse interpretation: The role of frame and perspective. Amsterdam/Philadelphia:John Benjamins Publishing.

Fauconnier, G., \& Sweetser, E. (1996). Spaces, worlds and grammar (p. 5). Chicago/London: University of Chicago Press.

Gile, D. (1995). Basic concepts and models for interpreter and translator training. Amsterdam \& Philadelphia: John Benjamins. Goffman, E. (1974). Frame analysis: An essay on the organization of experience (p. 21). Cambridge: Harvard University Press. Gumperz, J. J. (1982). Discourse strategies. Cambridge: Cambridge University Press.

Hohendahl, P. U. (1977). Introduction to reception aesthetics. New German Critique, 10, 29-63.

Holub, R. C. (1992). Crossing borders: Reception theory, poststructuralism, deconstruction. Madison: U of Wisconsin P.

John Rawls. (n.d.). In Wikipedia. Retrieved from https://en.wikipedia.org/wiki/John_Rawls

LIU, J. (2010). Perspective in language expression. Foreign Language Research, 4, 41.

Minsky, M. (1986). The society of mind (p. 261). New York: Simon 8c Schuster.

Rawls, J. (1971). A theory of justice (Original ed.). Cambridge, Mass.: Belknap Press of Harvard University Press.

Rawls, J. (2001). Justice as fairness: A restatement (2nd ed.). Cambridge, Mass.: Harvard University Press.

REN, R. (2010). On translator's visibility. Journal of Northeastern University (Social Science), 12(6), 540-544, 555. 
REN, R. (Ed.). (2014). An introduction to interpretation for graduates (Chinese ed.). Shenyang: Northeastern University Press.

SU, W. (2010). "Conduit" or "Mediator": An empirical study of the role of the medical interpreter. Journal of Foreign Languages Research, 6(5), 84-88. 